\title{
Henoch-Schönlein Purpura in children: not only kidney but also lung
}

\author{
Giada Maria Di Pietro ${ }^{1}$, Massimo Luca Castellazzi ${ }^{2}$, Antonio Mastrangelo ${ }^{3}$, Giovanni Montini ${ }^{3}$, Paola Marchisio ${ }^{1}$ and \\ Claudia Tagliabue ${ }^{4^{*}}$
}

\begin{abstract}
Background: Henoch-Schönlein Purpura (HSP) is the most common vasculitis of childhood and affects the small blood vessels. Pulmonary involvement is a rare complication of HSP and diffuse alveolar hemorrhage (DAH) is the most frequent clinical presentation. Little is known about the real incidence of lung involvement during HSP in the pediatric age and about its diagnosis, management and outcome.

Methods: In order to discuss the main clinical findings and the diagnosis and management of lung involvement in children with HSP, we performed a review of the literature of the last 40 years.

Results: We identified 23 pediatric cases of HSP with lung involvement. DAH was the most frequent clinical presentation of the disease. Although it can be identified by chest $x$-ray (CXR), bronchoalveolar lavage (BAL) is the gold standard for diagnosis. Pulse methylprednisolone is the first-line of therapy in children with DAH. An immunosuppressive regimen consisting of cyclophosphamide or azathioprine plus corticosteroids is required when respiratory failure occurs. Four of the twenty-three patients died, while 18 children had a resolution of the pulmonary involvement.
\end{abstract}

Conclusions: DAH is a life-threatening complication of HSP. Prompt diagnosis and adequate treatment are essential in order to achieve the best outcome.

Keywords: Henoch-Schönlein Purpura, IgA Vasculitis, Pulmonary involvement, Diffuse alveolar hemorrhage, Children

\section{Background}

Henoch-Schönlein purpura (HSP), also known as anaphylactoid purpura or, most recently, IgA Vasculitis (IgAV), is the most common leukocytoclastic systemic small-vessel vasculitis in childhood [1]. It is usually characterised by non-thrombocytopenic purpura, with typical purple, non-blanching papules, localised primarily on the lower extremities and buttocks. It can also be associated with abdominal discomfort, joint symptoms such as arthritis or arthralgia of large joints of the lower extremities, and risk of renal involvement [2].

The range of clinical manifestations of HSP is very broad, varying from asymptomatic microscopic hematuria to proteinuria and acute kidney injury (AKI) of various degrees up to rapidly progressive glomerulonephritis with

\footnotetext{
* Correspondence: claudia.tagliabue@policlinico.mi.it

${ }^{4}$ Fondazione IRCCS Ca' Granda Ospedale Maggiore Policlinico, Pediatric

Highly Intensive Care Unit, 20122 Milan, Italy

Full list of author information is available at the end of the article
}

significant risk of chronic renal impairment [3]. Other possible organ involvement includes cerebral vasculitis, ureteral or bladder disease, and scrotal, penile or testicular hemorrhage [4-6].

Piram et al., in a review published in 2013, estimated the annual incidence of HSP in children to be between 3 and $26.7 / 100,000$, demonstrating that it occurs two to 33 times more frequently in infants than in adults [7].

HSP is usually a self-limiting disease with an average duration of 4 weeks; it can have a remitting-relapses course especially within 3 months after initial resolution and rarely, when complicated, it can be fatal [8].

Although the etiology remains unknown, a possible link between genetic predisposition and environmental factors are considered crucial for the pathogenesis of HSP $[9,10]$.

The diagnosis of HSP is based on clinical findings. The diagnostic criteria for HSP were recently revised by various study groups (EULAR European League Against

(c) The Author(s). 2019 Open Access This article is distributed under the terms of the Creative Commons Attribution 4.0 International License (http://creativecommons.org/licenses/by/4.0/), which permits unrestricted use, distribution, and 
Table 1 EULAR/PRINTO/PRES diagnostic criteria of HenochSchönlein Purpura

Palpable non-thrombocytopenic purpura (mandatory criterion) with lower limb predominance in the presence of at least one of the following four features:

- Abdominal pain

- Histopathology showing typical leukocytoclastic vasculitis with predominant IgA deposition or proliferative glomerulonephritis with predominant IgA deposition

- Arthritis (acute, any joint) or arthralgia

- Renal involvement (any hematuria and/or proteinuria)

Rheumatism, PRINTO Pediatric Rheumatology International Trials Organisation and PRES Pediatric Rheumatology European Society), and are listed in Table $1[11,12]$.

Pulmonary involvement in HSP is a rare but severe complication and its presence increases the vasculitis morbidity and mortality rates [13-16].

Lung involvement in children with HSP is extremely rare. In particular, sub-clinical lung impairment without respiratory symptoms assessed by pulmonary function tests has been seen during the active phase of the disease, suggesting that the course of the disease involves a malfunction of the alveolar-capillary membrane due to the deposition of immune complexes containing IgA within the vessels of the alveolar septa [17-19].

Chaussen et al. reported a decrease in lung transfer for carbon monoxide (TLCO) in 28 out of 29 patients with HSP without pulmonary symptoms, with normal lung volumes and normal blood gas values, although mild radiological signs of interstitial lung involvement were observed in 18 of 26 patients. In all cases, the TLCO values normalised after complete clinical recovery [20].

TLCO impairment is associated with granular immune complex deposition, neutrophilic interstitial infiltration (acute inflammation), fibrin deposition and consequent fibrinoid necrosis, finally resulting in a thickening of the capillary wall. Nuclear debris may be present in the interstitium, representing leukocytoclasis [21, 22].

This hypothesis is supported by the results of autopsies on patients who died of diffuse alveolar hemorrhage (DAH), which were characterised by pulmonary edema with intra-alveolar hemorrhage, interstitial fibrosis, arterial neutrophilic infiltrate, loss of nuclear staining in the alveolar walls and septa, and capillary wall necrosis. The immunochemistry examination shows granular deposition of IgA along the alveolar septa, suggesting an immune pathogenesis $[23,24]$.

The absence of IgA on the lung biopsy does not rule out a potential role in the pathogenetic mechanism, due to the rapidity of the immunofluorescence changes, for example on the skin, where IgA disappears just a few days after its deposition [25, 26].
Massive lung involvement such as DAH is rare, especially in the pediatric age. Patients with pulmonary hemorrhage have kidney involvement in up to $95 \%$ of cases, more than double the percentage of patients with no pulmonary involvement, sign of the presence of a more severe disease [27, 28].

The aim of this review is to provide a critical appraisal of the medical literature regarding the lung involvement in HSP in children.

\section{Methods}

A research of the literature was performed in PUBMED database, using the terms "Henoch-Schönlein Purpura", "anaphylactoid purpura", "Diffuse alveolar hemorrhage", "Pulmonary Involvement", "Children". Only those articles that were reported in English literature and included pediatric patients (0-18 years) with a HSP and lung involvement were included for this narrative review. We found 23 cases between 1979 and 2019, and we described symptoms, diagnostic findings, treatment and outcomes.

\section{Results}

Between 1979 and 2019, there were 23 pediatric casereports of children with HSP who developed DAH. The main findings of these case-reports are described in Table 2.

The average age at the onset of HSP with pulmonary involvement was 10.2 years, with little difference between males (12 cases) and females (11 cases).

Almost all children with pulmonary hemorrhage had renal involvement, ranging from hematuria often associated with proteinuria, to nephritis or nephrotic proteinuria through to AKI $[8,10,14,15,25-27,29-37,39]$. The co-occurrence of rapidly progressive glomerulonephritis and DAH is also known as "pulmonary renal syndrome" and it is primarily related to an autoimmune etiology. However, Gd-IgA1 pathway is probably involved, due to the presence of similar manifestation in other IgA related disorders, such as IgA nephropathy (IgAN), ANCA-associated vasculitis overlap syndrome, IgA-dominant post-infectious glomerulonephritis, IgAvariant Goodpasture's syndrome and IgA-producing monoclonal gammopathy [40-42].

Twelve of twenty-three children were screened for ANCA: 11 were negative and one was c-ANCA negative but p-ANCA positive (this patient had IgA deposition in kidney biopsy but the possibility of concurrent ANCA-associated vasculitis could not be excluded at all). Eleven of twenty-three children were not screened for ANCA: six of them did not perform kidney biopsy, three had IgA deposition in renal biopsy, two had other glomerular pattern with different deposits in biopsy. Almost all children had a normal complement screening 


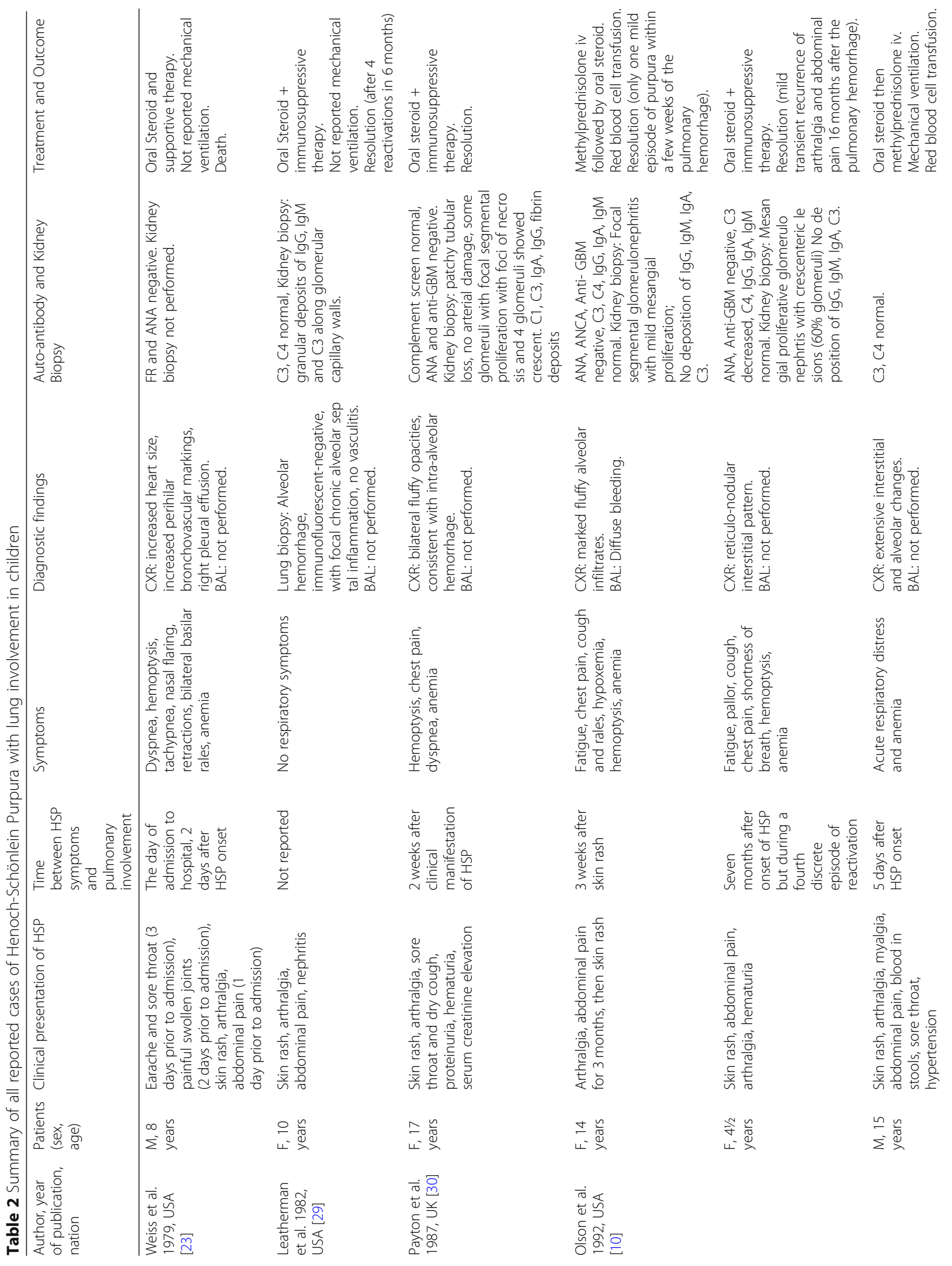




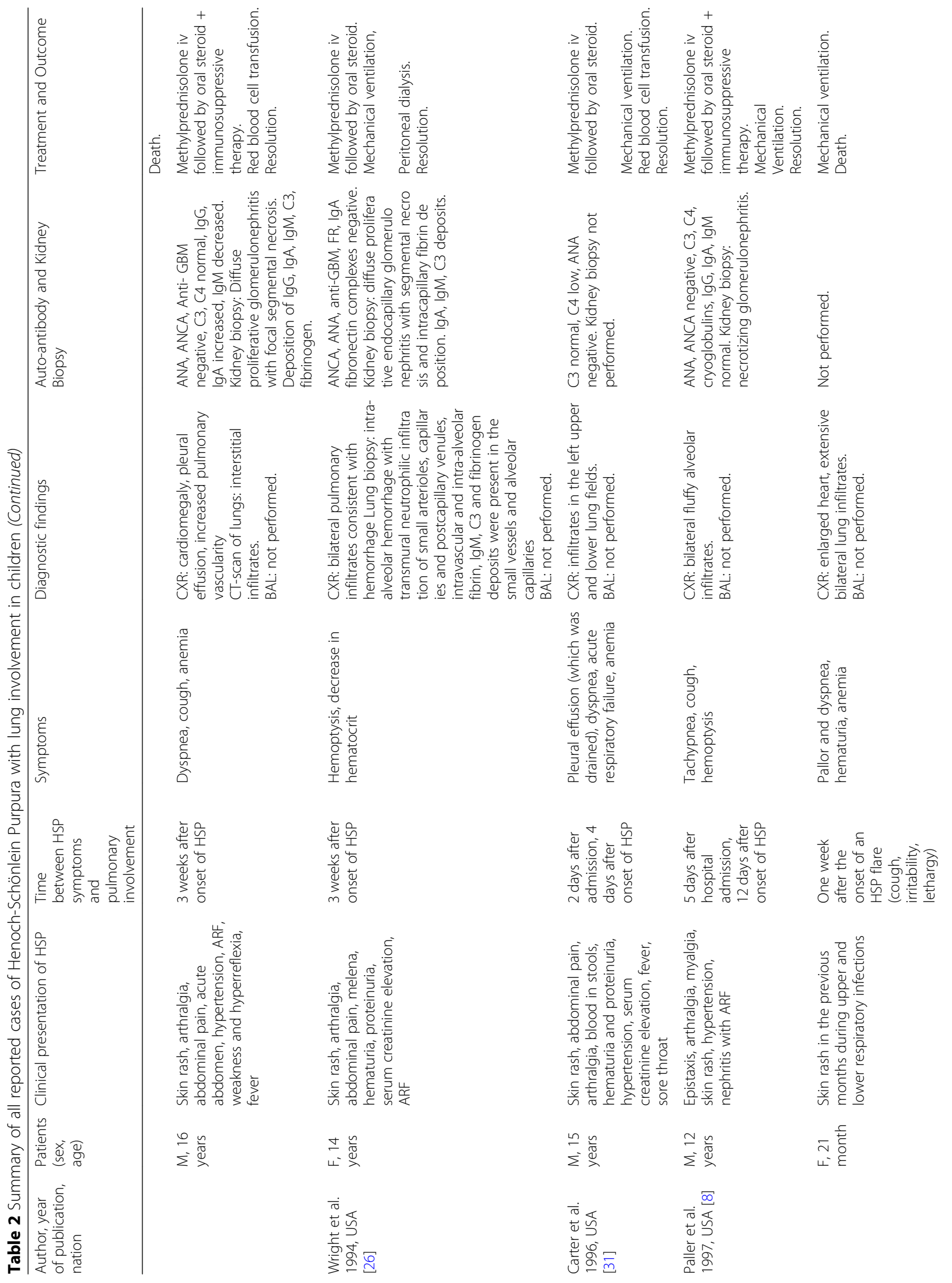




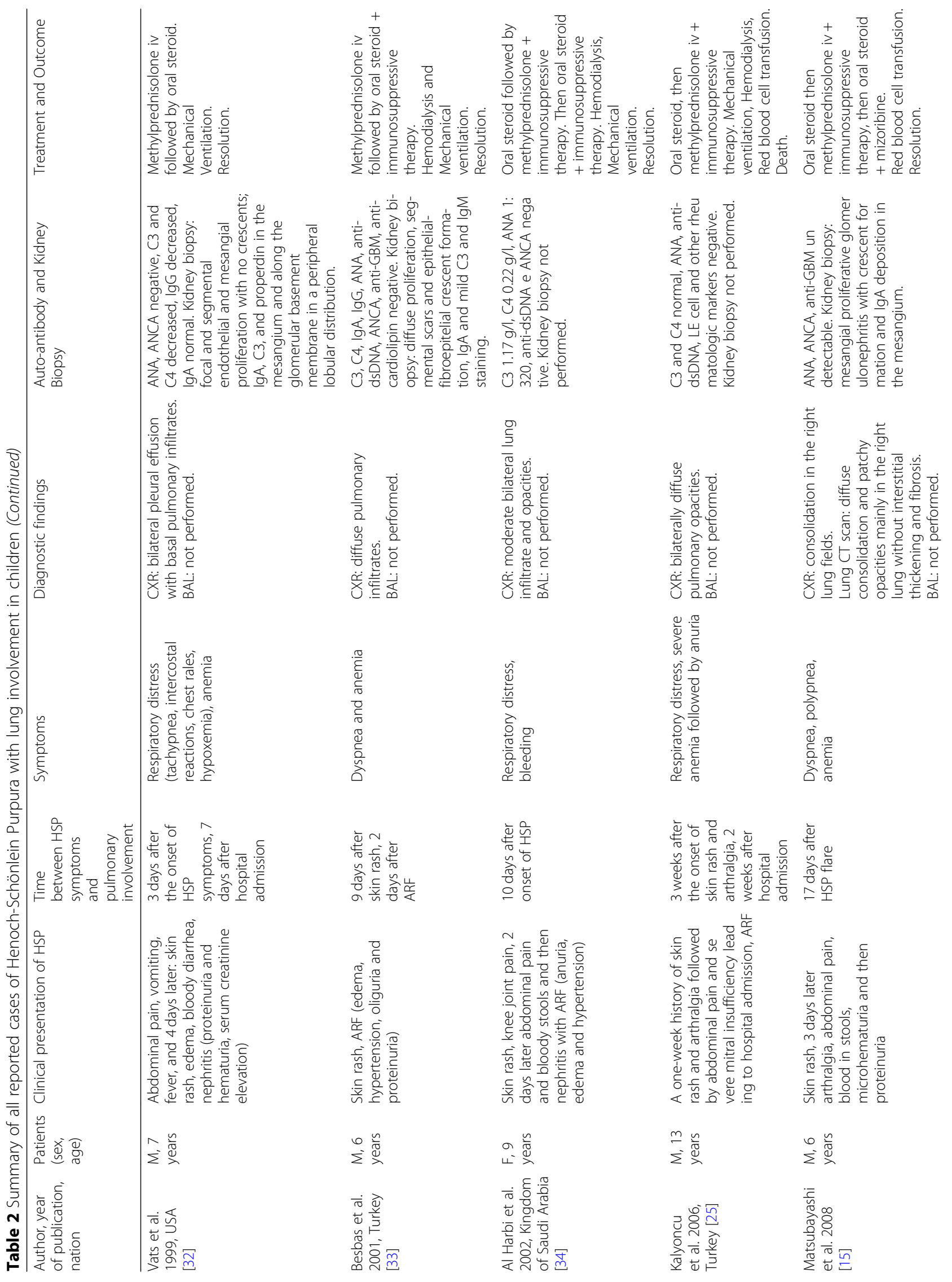




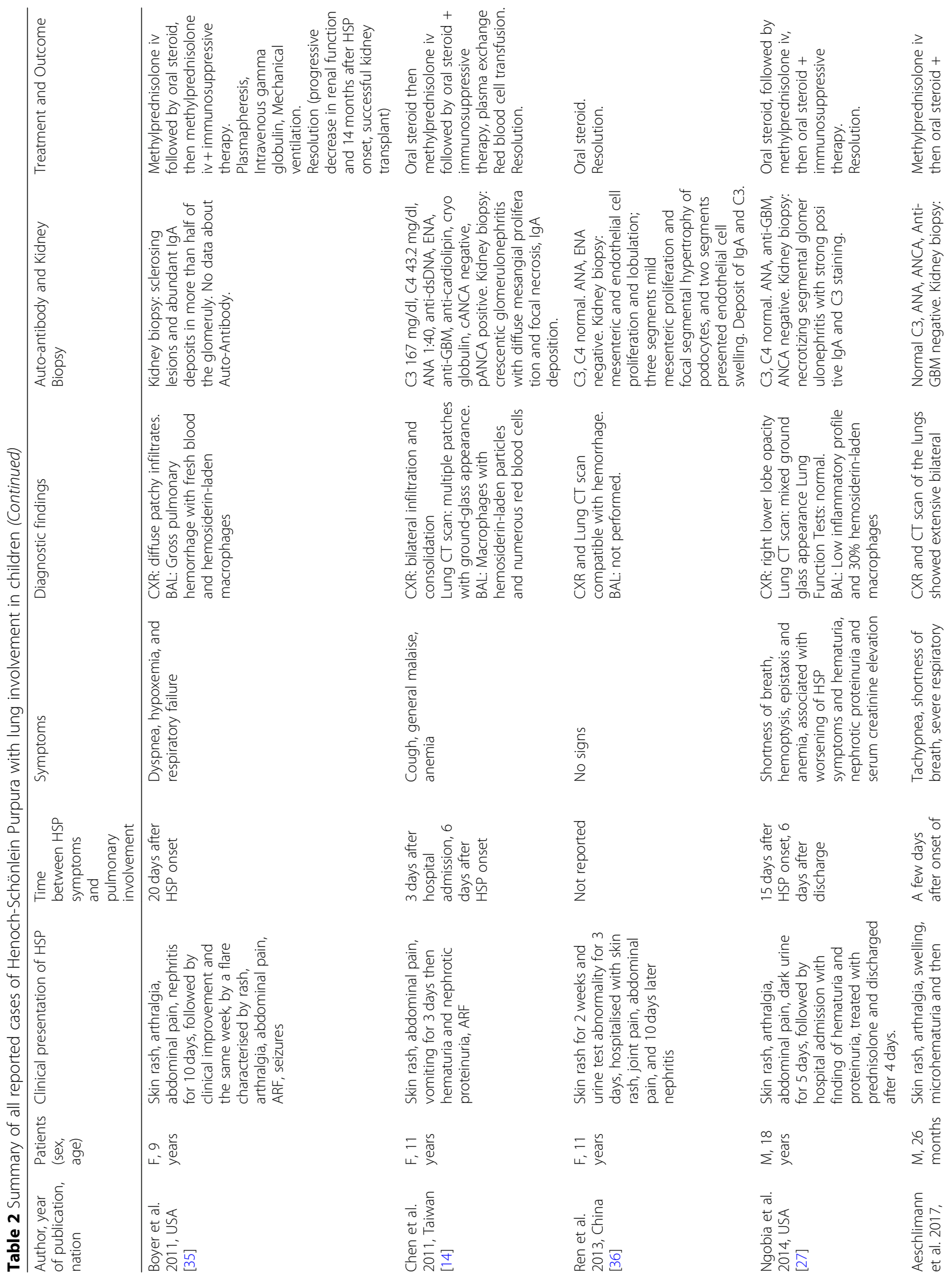




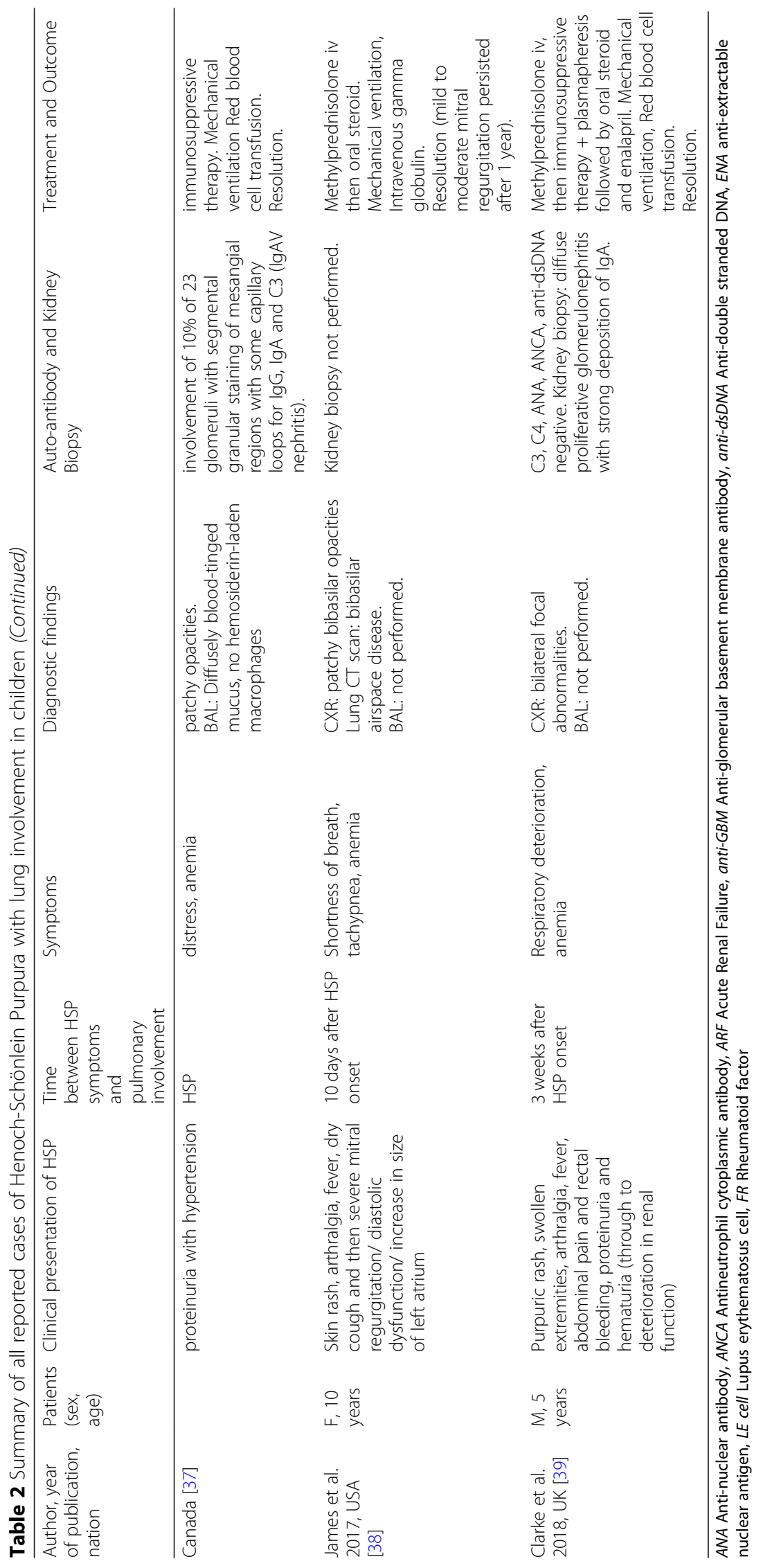


and negative auto-antibody research, so there are no markers which can predict a more severe course of the disease $[8,10,14,15,23,25-27,29-34,36-39]$.

In the majority of the cases, the pulmonary symptoms included cough, hemoptysis, epistaxis, dyspnea, tachypnea, chest pain and shortness of breath through to acute respiratory failure $[8,10,14,15,23,25-27,30-35$, 37-39]. However, pulmonary hemorrhage should be considered also in HSP patients with no respiratory symptoms or with common pulmonary manifestations. Two of twenty-three patients had no respiratory symptoms, but only radiological imaging findings suggestive of DAH $[29,36]$. So most but not all children with pulmonary vasculitis have respiratory symptoms, in some anemia or incidental radiological findings bring it to attention.

The time between the onset of the disease and the occurrence of the respiratory symptoms ranged from 2 days to 3 weeks, with a mean of 12 days $[8,10,14,15$, $23,25-27,30-35,37,38]$, except for 2 cases in which the timing was not reported due to the absence of these symptoms $[29,36]$.

The chest $\mathrm{x}$-ray (CXR) was the first diagnostic step for DAH, and in most cases showed a pattern of diffuse bilateral pulmonary infiltrates.

In some cases, due to a misinterpretation of the CXR findings, patients were treated with antibiotic therapy due to a suspicion of a lobar pneumonia instead of DAH $[10,27,37]$. For this reason, bronchoalveolar lavage (BAL) should be performed to confirm diagnosis and start treatment promptly. Five of twenty-three children had BAL performed; the typical findings ranged from the evidence of blood in the alveolar space in the acute phase, to the presence of hemosiderin-laden macrophages in chronic hemorrhage [14, 27, 35, 37, 43].

Eighteen of twenty-three children (78\%) had anemia and decreased hematocrit values due to pulmonary hemorrhage $[8,10,14,15,23,25-27,30-33,37,38]$, and nine $(39 \%)$ needed red blood cell transfusion [10, $14,15,25,31,37]$.

Thirteen children (56\%) required mechanical ventilation, 12 of whom for respiratory distress, and remaining patient for massive pulmonary hemorrhage $[8,10,25$, $26,31-35,37,38]$. The need for intubation was not reported for two patients $(8 \%)[23,29]$.

The two patients without respiratory symptoms achieved DAH resolution, in one case with oral prednisone therapy alone and in the other with oral prednisone plus azathioprine $[29,36]$. Four children with DAH died despite treatment $[8,10,23,25]$. In the remaining 17 surviving patients $(73 \%)$, at the time of pulmonary involvement, nine had required no therapy, three were being treated with oral prednisone and five with intravenous pulse methylprednisolone (due to the worsening of the kidney disease or to the massive lung involvement on the computed tomography scan).

Of the nine patients who had not been prescribed any medication, five of them needed mechanical ventilation and all of them achieved resolution with pulse methylprednisolone or with steroid treatment plus immunosuppressive therapy [10, 30-32, 36-38].

The three patients treated with oral prednisone did not need intubation and all survived after receiving pulse methylprednisolone with or without another immunosuppressive drug (cyclophosphamide) [14, 15, 27].

Of the five patients who were administered pulse methylprednisolone, all of them needed mechanical ventilation, three of them continued with pulse methylprednisolone, and for the other two cyclophosphamide was added to the intravenous steroid $[8,26,33-35]$.

Before the onset of respiratory symptoms, 12 of the 17 children were not taking any medication or were on oral prednisone $(2 \mathrm{mg} / \mathrm{kg} /$ day $)$, which could suggest that oral steroid (and not intravenous steroid) seems not to prevent pulmonary involvement. However, those patients on oral steroid therapy did not need mechanical ventilation. The absence of medication increased the risk of acute respiratory failure, so steroid therapy was recommended to avoid intubation and to reduce the mortality rate $[14,15,27]$.

No standard therapy was established for patients with HSP with pulmonary involvement; however, the first choice treatment was high-dose intravenous pulse methylprednisolone, with or without immunosuppressive therapy. Oral steroid therapy was ineffective for the prevention of lung involvement, considering that most patients were on oral steroids before the onset of DAH, although it did reduce the risk of acute respiratory failure $[14,19,36]$.

Four children died, the lung biopsy of three of them were characterised by atelectasis, pulmonary edema with intra-alveolar haemorrhage, interstitial fibrosis and diffuse iron deposition $[8,10,23,25]$. Among the 19 surviving patients, 16 had a resolution after the first episode, while three had a recurrent disease: the first repeated arthralgia and abdominal pains, the second a single mild episode of purpura and the third multiple reactivations $[8,10,14,15,26,27,29-39]$.

\section{Discussion and conclusion}

HSP is one of the most common small-vessel vasculitis in children. It is generally a self-limiting disease in which the most feared complication is renal involvement.

Although rare, lung involvement in patients with HSP could be asymptomatic and should be investigated in order to diagnose potential lung involvement, due to a disease progression to a more severe clinical presentation, such as DAH. TLCO could be performed early in 
patients with HSP to evaluate the presence of pulmonary involvement even in the absence of symptoms, in order to perform more investigations and to begin the appropriate supportive treatment immediately. Indeed the carbon monoxide diffusing capacity tests is lower in children with HSP during the acute phase of the disease and normal during resolution of the disease.

In patients with DAH, the most common clinical findings are cough, hemoptysis, epistaxis, dyspnea, tachypnea, chest pain and shortness of breath through to acute respiratory failure that could require intubation and mechanical ventilation. Limited data are available for the prevention and treatment of lung involvement in HSP. It was observed that oral corticosteroids are not sufficient for the prevention of DAH, but they could reduce the need for mechanical ventilation. No guidelines regarding the treatment of DAH are so far available. Because of the disease progression and the common associated renal involvement, we suggest to treat every pulmonary complication with intravenous methylprednisolone, avoiding to wait an eventually life threatening complication as DAH. However, the best treatment for lung involvement in HSP is still a matter of debate and needs further researches.

Immunosuppressive treatment (azathioprine or cyclophosphamide) is indicated in presence of respiratory failure.

The limits of our article are that it is a narrative review and it is based almost on case reports or small case series. So, further multicentre studies on lung involvement in HSP are essential in order to define a diagnostic protocol, the best therapeutic strategies and their duration and the long-term outcomes.

\section{Abbreviations}

AKI: Acute kidney injury; BAL: Bronchoalveolar lavage; CXR: Chest x-ray; DAH: Diffuse alveolar hemorrhage; Gd-IgA1: O-galactosylated-IgA1; HSP: Henoch-Schönlein purpura; IgAV: IgA Vasculitis; TLCO: Lung transfer for carbon monoxide

\section{Acknowledgements}

Not applicable.

\section{Authors' contributions}

GMDP and MLC searched the literature and wrote the manuscript; CT and AM wrote and revised the manuscript; PM and GM supervised and helped in performing revision. All authors read and approved the final manuscript.

\section{Funding}

This review was supported by the Italian Ministry of Health (Ricerca Corrente 2019 850/01).

\section{Availability of data and materials}

Not applicable.

Ethics approval and consent to participate

Not applicable.

\section{Consent for publication}

Not applicable.

\section{Competing interests}

The authors declare that they have no competing interests.

\section{Author details}

${ }^{1}$ Fondazione IRCCS Ca' Granda Ospedale Maggiore Policlinico, Department of Pathophysiology and Transplantation, Pediatric Highly Intensive Care Unit, Università degli Studi di Milano, 20122 Milan, Italy. ${ }^{2}$ ASST NORDMILANO, Ospedale di Sesto San Giovanni, Pediatric and Neonatology Unit, Sesto San Giovanni, 20099 Milan, Italy. ${ }^{3}$ Fondazione IRCCS Ca' Granda Ospedale Maggiore Policlinico, Department of Clinical Sciences and Community Health, Pediatric Nephrology and Dialysis Unit, Università degli Studi di Milano, 20122 Milan, Italy. ${ }^{4}$ Fondazione IRCCS Ca' Granda Ospedale Maggiore Policlinico, Pediatric Highly Intensive Care Unit, 20122 Milan, Italy.

Received: 16 July 2019 Accepted: 12 November 2019

Published online: 21 November 2019

\section{References}

1. Jennette JC, Falk RJ, Bacon PA, Basu N, Cid MC, Ferrario F, Flores-Suarez LF, Gross WL, Guillevin L, Hagen EC, Hoffman GS, Jayne DR, Kallenberg CG, Lamprecht P, Langford CA, Luqmani RA, Mahr AD, Matteson EL, Merkel PA, Ozen S, Pusey CD, Rasmussen N, Rees AJ, Scott DG, Specks U, Stone JH, Takahashi K, Watts RA. 2012 revised international Chapel Hill consensus conference nomenclature of vasculitides. Arthritis Rheum. 2013;65(1):1-11.

2. Trnka P. Henoch-Schönlein purpura in children. J Paediatr Child Health. 2013:49(12):995-1003.

3. Chen JY, Mao JH. Henoch-Schönlein purpura nephritis in children: incidence, pathogenesis and management. World J Pediatr. 2015;11(1): 29-34.

4. Garzoni L, Vanoni F, Rizzi M, Simonetti GD, Goeggel Simonetti B, Ramelli GP, Bianchetti MG. Nervous system dysfunction in Henoch-Schonlein syndrome: systematic review of the literature. Rheumatology (Oxford). 2009;48(12): 1524-9.

5. Siegenthaler GM, Rizzi M, Bettinelli A, Simonetti GD, Ferrarini A, Bianchetti MG. Ureteral or vesical involvement in Henoch-Schönlein syndrome: a systematic review of the literature. Pediatr Nephrol. 2014;29(2):235-9.

6. Ferrara P, Marrone G, Nicoletti A, Mastrangelo A, Tiberi E, Rigante D, Stabile A. Penile involvement in Henoch-Schönlein purpura with good prognosis. Scand J Urol Nephrol. 2007:41(6):567-9.

7. Piram M, Mahr A. Epidemiology of immunoglobulin A vasculitis (HenochSchönlein): current state of knowledge. Curr Opin Rheumatol. 2013;25(2): 171-8.

8. Paller AS, Kelly K, Sethi R. Pulmonary hemorrhage: an often fatal complication of Henoch-Schoenlein purpura. Pediatr Dermatol. 1997;14(4): 299-302.

9. Rigante D, Castellazzi L, Bosco A, Esposito S. Is there a crossroad between infections, genetics, and Henoch-Schönlein purpura? Autoimmun Rev. 2013; 12(10):1016-21.

10. Olson JC, Kelly KJ, Pan CG, Wortmann DW. Pulmonary disease with hemorrhage in Henoch-Schöenlein purpura. Pediatrics. 1992;89(6 Pt 2): 1177-81.

11. Ozen S, Pistorio A, lusan SM, Bakkaloglu A, Herlin T, Brik R, Buoncompagni A Lazar C, Bilge I, Uziel Y, Rigante D, Cantarini L, Hilario MO, Silva CA, Alegria M, Norambuena X, Belot A, Berkun Y, Estrella Al, Olivieri AN, Alpigiani MG, Rumba I, Sztajnbok F, Tambic-Bukovac L, Breda L, Al-Mayouf S, Mihaylova D, Chasnyk V, Sengler C, Klein-Gitelman M, Djeddi D, Nuno L, Pruunsild C, Brunner J, Kondi A, Pagava K, Pederzoli S, Martini A, Ruperto N, Paediatric Rheumatology International Trials Organisation (PRINTO). EULAR/PRINTO/ PRES criteria for Henoch-Schönlein purpura, childhood polyarteritis nodosa, childhood Wegener granulomatosis and childhood Takayasu arteritis: Ankara 2008. Part II: final classification criteria. Ann Rheum Dis. 2010;69(5): 798-806.

12. Ozen S, Marks SD, Brogan P, Groot N, de Graeff N, Avcin T, Bader-Meunier B, Dolezalova P, Feldman BM, Kone-Paut I, Lahdenne P, McCann L, Pilkington C, Ravelli A, van Royen A, Uziel Y, Vastert B, Wulffraat N, Kamphuis S, Beresford MW. European consensus-based recommendations for diagnosis and treatment of immunoglobulin A vasculitis-the SHARE initiative. Rheumatology (Oxford). 2019;58(9):1607-16.

13. Levy M, Broyer M, Arsan A, Levy-Bentolila D, Habib R. Anaphylactoid purpura nephritis in childhood: natural history and immunopathology. Adv Nephrol Necker Hosp. 1976;6:183-228. 
14. Chen SY, Chang KC, Yu MC, Asueh S, Ou LS. Pulmonary hemorrhage associated with Henoch-Schönlein purpura in pediatric patients: case report and review of the literature. Semin Arthritis Rheum. 2011;41(2):305-12.

15. Matsubayashi R, Matsubayashi T, Fujita N, Yokota T, Ohro Y, Enoki H. Pulmonary hemorrhage associated with Henoch-Schönlein purpura in a child. Clin Rheumatol. 2008;27(6):803-5.

16. Nadrous HF, Yu AC, Specks U, Ryu JH. Pulmonary involvement in HenochSchönlein purpura. Mayo Clin Proc. 2004;79(9):1151-7.

17. Grabska-Kobylecka I, Nowak D, Wlodarczyk A, Bialasiewicz P. No impairment of pulmonary function in children with Henoch-Schonlein purpura after 4 year follow-up. Clin Rheumatol. 2016:35(11):2847-50.

18. Manganelli P, Fietta P, Carotti M, Pesci A, Salaffi F. Respiratory system involvement in systemic vasculitides. Clin Exp Rheumatol. 2006;24(2 Suppl 41):S48-59.

19. Rajagopala S, Shobha V, Devaraj U, D'Souza G, Garg I. Pulmonary hemorrhage in Henoch-Schönlein purpura: case report and systematic review of the english literature. Semin Arthritis Rheum. 2013:42(4):391-400

20. Chaussain M, de Boissieu D, Kalifa G, Epelbaum S, Niaudet P, Badoual J, Gendrel D. Impairment of lung diffusion capacity in Schönlein-Henoch purpura. J Pediatr. 1992;121(1):12-6.

21. Cazzato S, Bernardi F, Cinti C, Tassinari D, Canzi A, Bergamaschi R, Corsini I, Capecchi V, Cacciari E. Pulmonary function abnormalities in children with Henoch-Schönlein purpura. Eur Respir J. 1999;13(3):597-601.

22. Fishbein GA, Fishbein MC. Lung vasculitis and alveolar hemorrhage: pathology. Semin Respir Crit Care Med. 2011;32(3):254-63.

23. Weiss VF, Naidu S. Fatal pulmonary hemorrhage in Henoch-Schönlein purpura. Cutis. 1979;23(5):687-8

24. Markus HS, Clark JV. Pulmonary haemorrhage in Henoch-Schönlein purpura. Thorax. 1989;44(6):525-6.

25. Kalyoncu M, Cakir M, Erduran E, Okten A. Henoch-Schönlein purpura: a case with atypical presentation. Rheumatol Int. 2006;26(7):669-71.

26. Wright WK, Krous HF, Griswold WR, Billman GF, Eichenfield LF, Lemire JM, Reznik VM. Pulmonary vasculitis with hemorrhage in anaphylactoid purpura. Pediatr Pulmonol. 1994;17(4):269-71.

27. Ngobia A, Alsaied T, Unaka NI. Henoch-Schönlein purpura with hemoptysis: is it pneumonia or something else? Hosp Pediatr. 2014;4(5):316-20.

28. Kraft DM, Mckee D, Scott C. Henoch-Schönlein purpura: a review. Am Fam Physician. 1998:58(2):405-8 411

29. Leatherman JW, Sibley RK, Davies SF. Diffuse intrapulmonary hemorrhage and glomerulonephritis unrelated to anti-glomerular basement membrane antibody. Am J Med. 1982;72(3):401-10.

30. Payton CD, Allison ME, Boulton-Jones JM. Henoch Schonlein purpura presenting with pulmonary haemorrhage. Scott Med J. 1987;32(1):26-7.

31. Carter ER, Guevara JP, Moffitt DR. Pulmonary hemorrhage in an adolescent with Henoch-Schönlein purpura. West J Med. 1996;164(2):171-3.

32. Vats KR, Vats A, Kim Y, Dassenko D, Sinaiko AR. Henoch-Schönlein purpura and pulmonary hemorrhage: a report and literature review. Pediatr Nephrol. 1999;13(6):530-4.

33. Besbas N, Duzova A, Topaloglu R, Gok F, Ozaltin F, Ozen S, Bakkaloglu A Pulmonary haemorrhage in a 6-year-old boy with Henoch-Schönlein purpura. Clin Rheumatol. 2001;20(4):293-6.

34. Al-Harbi NN. Henoch-Schönlein nephritis complicated with pulmonary hemorrhage but treated successfully. Pediatr Nephrol. 2002;17(9):762-4.

35. Boyer EM, Turman M, O'Neil KM. Partial response to anakinra in lifethreatening Henoch-Schönlein purpura: case report. Pediatr Rheumatol Online J. 2011;9(1):21.

36. Ren X, Zhang W, Dang W, Zhai W, Guo Q, Ding Y, Yang X. A case of anaphylactoid purpura nephritis accompanied by pulmonary hemorrhage and review of the literature. Exp Ther Med. 2013;5(5):1385-8.

37. Aeschlimann FA, Yeung RSM, Laxer RM, Hebert D, Cooper A, Chami R, Noone D. A toddler presenting with pulmonary renal syndrome. Case Rep Nephrol Dial. 2017:7(2):73-80

38. James CA, Gonzalez I, Khandhar P, Freij BJ. Severe mitral regurgitation in a child with henoch-schönlein purpura and pulmonary hemorrhage. Glob Pediatr Health. 2017;4. https://doi.org/10.1177/2333794X17726940.

39. Clarke K, Kurteva E, Sebire NJ, Al-Obaidi M. Pulmonary renal syndrome in Henoch-Schönlein purpura. Arch Dis Child. 2018. https://doi.org/10.1136/ archdischild-2018-315030.

40. Rajagopala S, Parameswaran S, Ajmera JS, Ganesh RN, Katrevula A. Diffuse alveolar hemorrhage in IgA nephropathy: case series and systematic review of the literature. Int J Rheum Dis. 2017;20(1):109-21.
41. von Vigier RO, Trummler SA, Laux-End R, Sauvain MJ, Truttmann AC, Bianchetti MG. Pulmonary renal syndrome in childhood: a report of twentyone cases and a review of the literature. Pediatr Pulmonol. 2000;29(5):382-8.

42. Knoppova B, Reily C, Maillard N, Rizk DV, Moldoveanu Z, Mestecky J, Raska M, Renfrow MB, Julian BA, Novak J. The origin and activities of IgA1-containing immune complexes in IgA nephropathy. Front Immunol. 2016;7:117.

43. Green RJ, Ruoss SJ, Kraft SA, Duncan SR, Berry GJ, Raffin TA. Pulmonary capillaritis and alveolar hemorrhage. Update on diagnosis and management. Chest. 1996;110(5):1305-16.

\section{Publisher's Note}

Springer Nature remains neutral with regard to jurisdictional claims in published maps and institutional affiliations.
Ready to submit your research? Choose BMC and benefit from:

- fast, convenient online submission

- thorough peer review by experienced researchers in your field

- rapid publication on acceptance

- support for research data, including large and complex data types

- gold Open Access which fosters wider collaboration and increased citations

- maximum visibility for your research: over $100 \mathrm{M}$ website views per year

At BMC, research is always in progress.

Learn more biomedcentral.com/submissions 